\title{
Influence of shoulder stabilization exercises on hand grip strength in children with Down syndrome: randomized clinical trial
}

\author{
Noha Elserty ${ }^{1,2^{*}}$ (D) and Eman Wagdy ${ }^{3}$ (D)
}

\begin{abstract}
Background: Children with Down syndrome (DS) are characterized by hypotonia resulting in reduced grip and pinch strength. This study aimed to investigate the influence of shoulder stabilization exercises on hand grip strength in children with Down syndrome. Thirty children with DS assigned randomly into 2 groups each group consists of 15 children. Handheld Dynamometer was used to measure grip strength and different pinch grasps for both groups before and after treatment. Both groups receive the same vocational school activities and the study group receives shoulder stabilization exercises for 3 months.
\end{abstract}

Results: Results revealed significant increase in the grip strength and different pinch grasps for dominant and nondominant hands post-treatment in both groups as the main effect of time was statistically significant. Study group showed significant improvement than the control group post-treatment as the main effect of group and time $x$ group interaction effect was statistically significant for dominant and non-dominant hands.

Conclusion: Shoulder stabilization exercises and regular vocational school activities have a positive effect on different grip strength in children with Down syndrome.

Trial registration: PACTR201907896910981. Registered 5 July 2019. A written consent form was introduced to all participant and signed by their parents.

\section{Background}

Down syndrome (DS) is one of the most common congenital genetic disorders, firstly described by Dr. John Langdon Down in 1866, attributed to chromosomal abnormality (Extra chromosome 21) called trisomy 21 [1-4]. The clinical presentation of DS is varied and includes different disorders as metabolic disorders, internal organs disorders, orthopedic, cardiovascular, neuromuscular, and visual impairments $[5,6]$. Child with DS had a developmental disability that affects gross and fine motor skills and characterized by certain morphological features, as abnormalities of head and limbs, short stature, muscular

\footnotetext{
*Correspondence: nelserty@ecu.edu.eg; noha_elserty@hotmail.com ${ }^{1}$ Basic Science Department, Faculty of Physical Therapy, Egyptian Chinese University, Cairo 11765, Egypt

${ }^{2}$ Fellow of Physical Therapy at Elsahel teaching hospital, Cairo, Egypt Full list of author information is available at the end of the article
}

hypotonia, and ligamentous laxity [7, 8]. Different studies postulated that muscle strength in child with DS is affected and many muscles in both upper and lower limbs [9-11]. Child with DS also suffered from obesity and intellectual disabilities, these factors beside the physical disabilities also contribute to the reduced motor capacity [12]. Amongst the common characteristics of the syndrome, some authors mention small and thick hands, with short fingers and an arched little finger, which could cause some difficulties in manipulative activities [13-15]. Reduced hand grip strength in child with DS will contribute to difficulty of the manipulative skills of child's hand and their functional activities [16]. Power of hand grip in child with DS can be measured by hand dynamometer. Different factors affect this measurement such as the anthropometric parameters of the hands like hand span, fingers length as well as the position of shoulder, elbow, and wrist joints

\section{Springer Open}

(c) The Author(s). 2020 Open Access This article is licensed under a Creative Commons Attribution 4.0 International License, which permits use, sharing, adaptation, distribution and reproduction in any medium or format, as long as you give appropriate credit to the original author(s) and the source, provide a link to the Creative Commons licence, and indicate if changes were made. The images or other third party material in this article are included in the article's Creative Commons licence, unless indicated otherwise in a credit line to the material. If material is not included in the article's Creative Commons licence and your intended use is not permitted by statutory regulation or exceeds the permitted use, you will need to obtain permission directly from the copyright holder. To view a copy of this licence, visit http://creativecommons.org/licenses/by/4.0/. 
[17]. Hand grip requires interaction between not only fingers and wrist joint but also it requires a good function of the whole upper limb, and it needs appropriate muscle activation in a proper sequence with the proper muscle strength [18]. Different studies relate the power of hand grip and shoulder muscles activity, and it was stated that shoulder muscles activities increase with the higher hand grip strength also; it was also postulated that there are strong relationships between the power of hand grip and shoulder stabilizer muscles regardless the dominance in healthy volunteers $[19,20]$. The power of hand grip could be used to monitor strength of stabilizers muscles of shoulder joint [21]. This may be explained by the role of shoulder muscles during whole arm activity; during movement of upper limb, shoulder stabilizer muscles play an important role in stabilizing humerus and scapula in their positions allowing proper shoulder stability which will improve the performance of upper extremity that would affect hand function [18]. This function of shoulder stabilizers gives the attention to exercising shoulder girdle muscle during rehabilitation of wrist joint as it was stated that shoulder exercise enhances the hand grip strength and improve the functional capability of hand [22]. Many studies emphasized that proper shoulder girdle muscles activation had a high impact on the hand manipulative skills [23-29]. Closed kinetic chain exercises are used for strengthening shoulder stabilizer muscles as it stimulates proprioceptors of joint and enhance dynamic stability of joints that improve function of the whole upper limb that would affect hand function [18]. So this study aimed to investigate the influence of shoulder stabilization exercise on hand grip strength in children with Down syndrome.

\section{Methods}

Study design

A randomized clinical trial

\section{Participants}

Thirty children with DS (16 boys and 14 girls) aged between 8 and 15 years old were recruited in this study from one of the schools for children with special needs, in East Cairo, in accordance with the code of ethics of the World Medical Association (Declaration of Helsinki) for experiments involving humans. This study was approved by ethical committee of the scientific research ethics committe of faculty of physical therapy, Beni-Suef University. All parents of the participating children in this study were informed about the nature and purpose of this study and signed an informed consent including their acceptance for participation and publication before starting the study procedure.

\section{Randomization, allocation, and blinding}

Concealed allocation was performed using a computergenerated randomized table of letters. Individual and sequentially lettered index cards were used to randomly assign children to the treatment groups. The index cards were placed in sealed envelopes. A therapist, blinded to baseline examination findings, opened the envelope and proceeded with treatment according to the group assignment. Each participant received a sealed envelope containing one of the letters A representing study group or $\mathrm{B}$ representing control group. CONSORT flow chart of the children allocation was made (Fig. 1).

Children were included in this study according to the following criteria:

1. Independent standing and walking

2. Functional hearing and vision

3. Mild and moderate mental retardation with IQ level (50-70) determined by a psychiatric specialist in the school (IQ measured by Stanford-Binet intelligence scale)

Children were excluded if they had any of the following criteria:

1. Pain and/or symptomatic neurologic/orthopedic dysfunction of upper or lower extremities

2. Cervical injury and chest wall disorders

3. Rheumatic and congenital heart disease

4. History of previous surgical operation

5. Regular participation in any sport activities

\section{Sample size estimation}

A preliminary power analysis (power $=0.8$ ) using G*Power software 3.1.9.2 (Neu-Isenburg, Germany) depending on data from pilot study prior to this study was used for sample size calculation. Fifteen subjects had been included in each group with an alpha level of 0.05 , and power $(1-\beta)$ of $80 \%$ with an effect size of 0.8 .

\section{Measures}

Jamar Hydraulic Hand Dynamometer was used to measure grip strength while lateral pinch, 2-point pinch, and 3-point pinch strength were measured by pinch gage. Jamar Hydraulic Hand Dynamometeris is the gold standard, valid, and reliable as a hand evaluation tool for routine screening and measuring of the isometric grip strength [30]. The dynamometer consists of dual-scale readout, a peak-hold needle, and an adjustable handle. The dynamometer has an adjustable handle for $1,1.5,2,2.5$, and 3-in. spacing. The scale of measurement used in the dynamometer is described in up to $200 \mathrm{lb}$. and/or $90 \mathrm{~kg}$. 


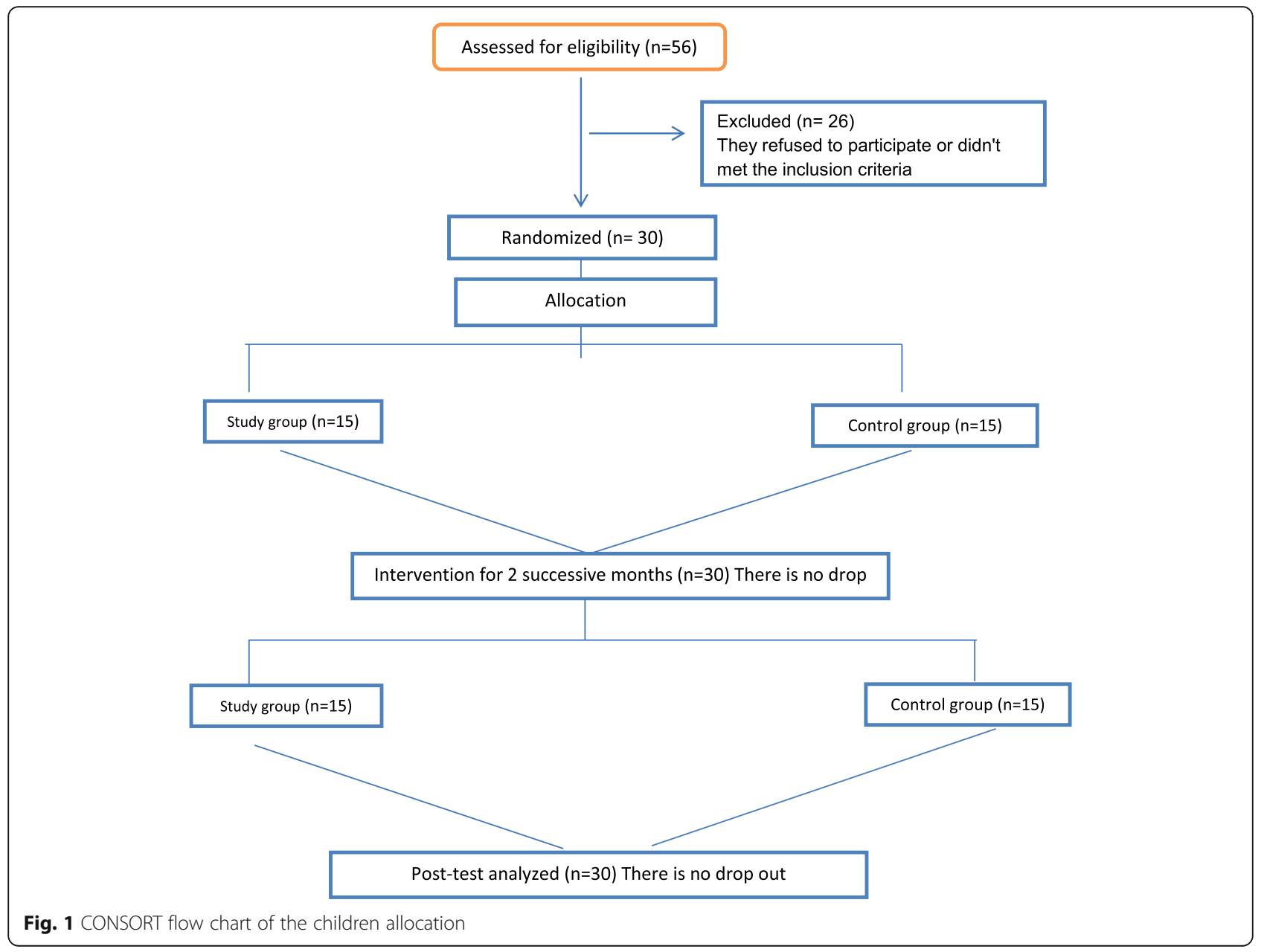

The measurements of grip and pinch strength were applied according to the recommendations of American Society of Hand Therapist [31]. Before using the dynamometer, the adjustable handle was set to the desired spacing (usually1.5 in. spacing used for standardization) and then the peak-hold needle adjusted to zero. One session was held before data collection to explain the evaluative procedures of different grasps that will be applied, and instructions were given to each child to be familiar with the device. Each child was instructed to set on a chair; chair height allowed the correct support of the feet and lumbar back. Child's shoulder was held in adduction and neutrally rotated, elbow flexed $90^{\circ}$, forearm neutral position, wrist between 0 and $30^{\circ}$ extension and $15^{\circ}$ ulnar deviation. Child was asked to press on the handle as much as he/she could, and the reading was recorded. Three repetitions were performed with 1-min rest interval and the mean of three trials was used for statistical analysis. Pinch gage was used to measure lateral pinch, 2-point pinch, and 3-point pinch strength. Pinch gage was held by the examiner at the distal end to prevent dropping. Scores were read on the needle side of the red readout marker. Child was asked to press on the gage as much as he can, and the reading was recorded. Three repetitions for each grasp were performed with 1min rest interval and the mean of three trials used for statistical analysis. All measurements applied for dominant and non-dominant hands [32]. All measurements were taken at the beginning of the study and after the end of the program.

\section{Procedure}

Treatment program in this study was based on the proximal dynamic neuromuscular stabilization (DNS) exercise which depends on exercising the shoulder stabilizer muscles using stabilization developmental pattern of a healthy infant [33]. Both study and control groups received the same vocational school activities, while study group received five shoulder stabilization exercises based on developmental positions. Exercises were explained for children using images that represent each position. In all exercises, each child was asked to keep the desired position with focusing on the point of support and keeping 
spine elongated, chin tucked, and shoulder blade adherent to rib cage.

First exercise was prone static exercise using prone position; in this position, shoulders are abducted 125$135^{\circ}$. The medial epicondyles of both elbows, bilateral anterior superior iliac spine, and symphysis pubis are in complete contact with the ground (Fig. 2). Second exercise was quadruped static exercise using quadruped position; hands and knees are the points of support in this exercise (Fig. 3). Third and fourth exercises were side sitting position with dominant arm support and side sitting with non-dominant arm support (Figs. 4 and 5). The child took the side sitting position and supporting on elbow and greater trochanter. Both legs are in slight hip and knee flexion. Finally, bear position was used to perform bear exercise. Bear exercise performed from quadruped position but with support on hands and tip toes not on knees. The child was instructed to keep knees and ankles not collapsed inward (Fig. 6). The child was asked to keep each position for $10 \mathrm{~s}$; exercises were conducted in 3 sets; each set consisted of 10 repetitions of each exercise with $3 \mathrm{~s}$ rest between each repetition and 1-3 min rest between each set depending on fatigue. This program was conducted 3 times per week for 3 successive months for both groups.

\section{Data analysis}

Data were analyzed for this study descriptively and with a $2 \times 2$ mixed-model analysis of variance (ANOVA) with the treatment groups (control vs. study) serving as the between-subjects factor and time of assessment (pretreatment, post-treatment) serving as the within subjects factor using the IBM SPSS version 21 software (IBM
Corp., Released 2012, IBM SPSS Statistics for Windows, Version 21.0, Armonk, NY), with $P$ value set at 0.05 . The dependent variables were grip strength, lateral pinch, 2-point pinch, and 3-point pinch. Prior to data analysis Shapiro-Wilk test and Levene's test were used to test the normality of the data and the equality of variances, respectively. The differences in demographic characteristics the both groups were assessed using unpaired $t$ tests and Chi-square test. Unpaired $t$ tests were also used to assess if there was a difference between the two groups in pre-treatment dependent variables.

\section{Results}

Demographic data of the children is presented in Table 1. No statistical differences were found between both groups in demographic data. Statistical diagnostic tests revealed no violations of the assumptions of normality and homogeneity of variance for any of the dependent variables. There was no significant difference between the two groups in all pre-treatment dependent variables $(P>0.05)$.

The a $2 \times 2$ mixed-model ANOVA analysis demonstrated significant increase in the grip strength for dominant and non-dominant hands post-treatment in both groups as the main effect of time was statistically significant $(0.0001)$. But study group showed significant improvement than the control group post-treatment as the main effect of group was statistically significant for dominant and non-dominant hands $(0.01$ and 0.02 , respectively), and time $\times$ group interaction effect was also significant (0.0001) for dominant and non-dominant hands as shown in Table 2.

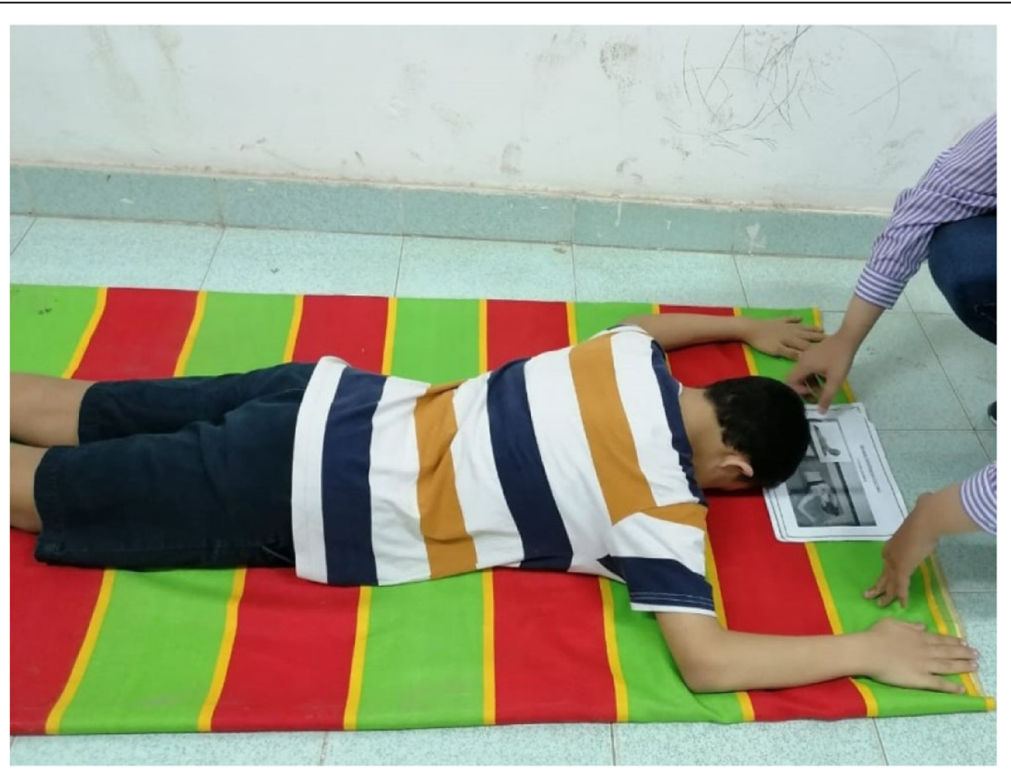

Fig. 2 Prone static exercise 


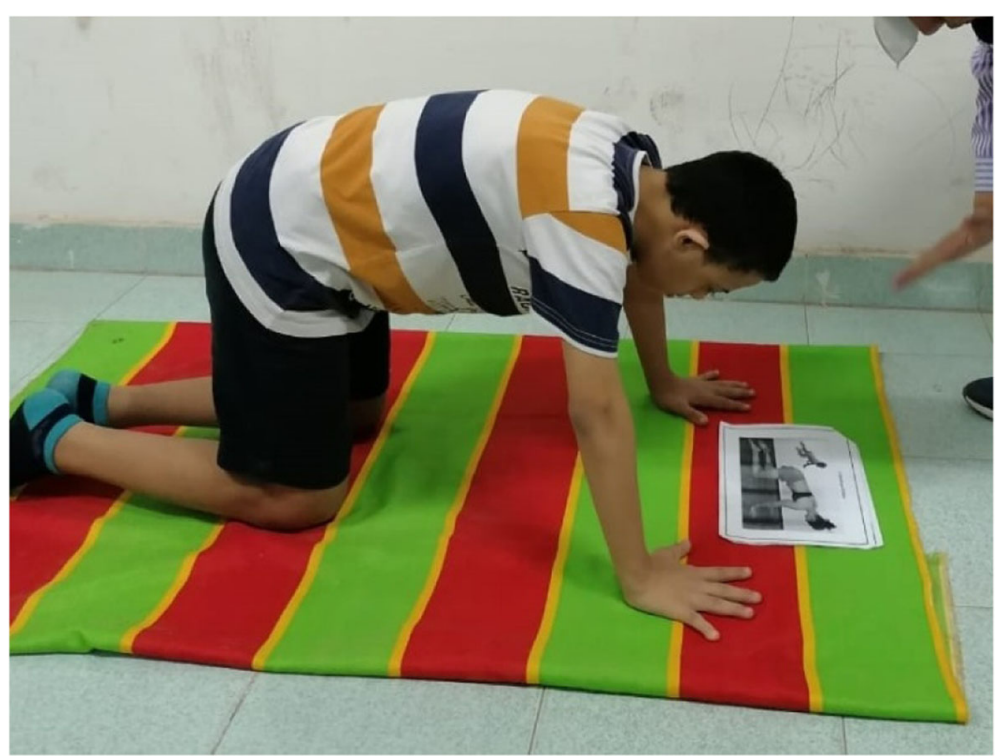

Fig. 3 Quadruped static exercise

Lateral pinch was significantly increased post-treatment in both groups for dominant and non-dominant hands as the main effect of time was statistically significant (0.0001). Also, study group showed significant improvement in the lateral pinch than control group posttreatment as the main effect of group was statistically significant for dominant and non-dominant hands (0.02 and 0.01 , respectively), and time $\times$ group interaction effect was also significant $(0.0001)$ as shown in Table 2.

Similar results were obtained for 2-point pinch as it showed significant increase in both groups post-treatment for dominant and non-dominant hands as the main effect of time was statistically significant (0.0001), and also, study group was superior to control group post-treatment as the main effect of group was statistically significant for dominant and non-dominant hands $(0.001$ and 0.001 , respectively), and time $\times$ group interaction effect was also significant $(0.0001)$ as shown in Table 2.

Furthermore, 3-point pinch showed significant increase in both groups post-treatment for dominant and non-dominant hands as the main effect of time was statistically significant $(0.0001)$. The study group showed significant improvement than control group posttreatment in 3-point pinch as the main effect of group

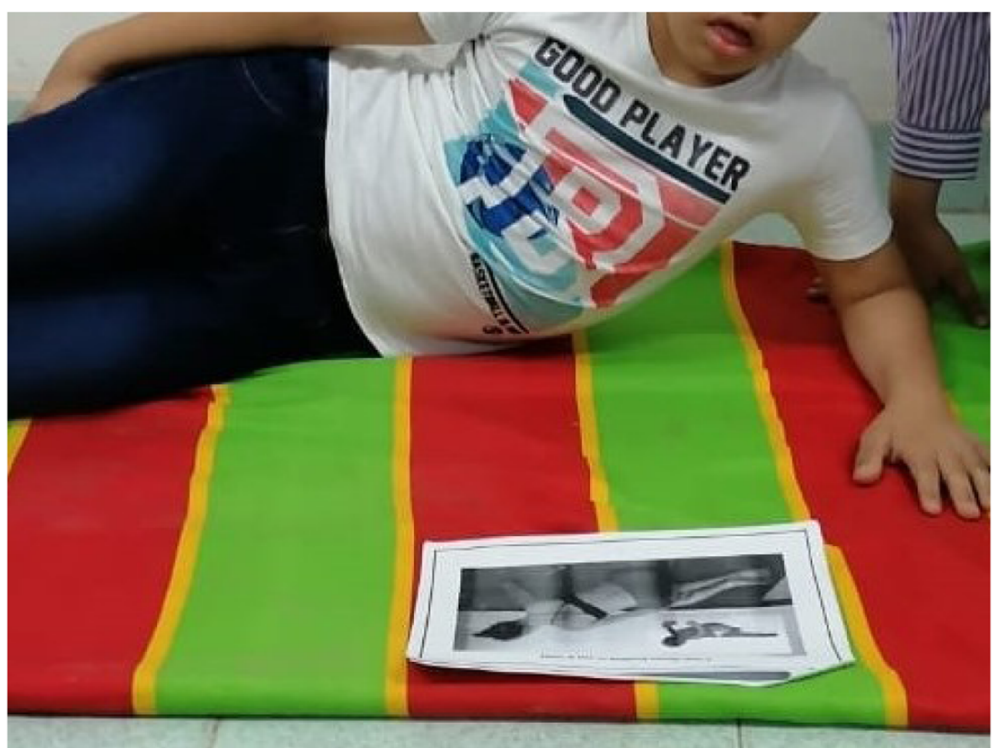

Fig. 4 Side sitting on dominant hand 


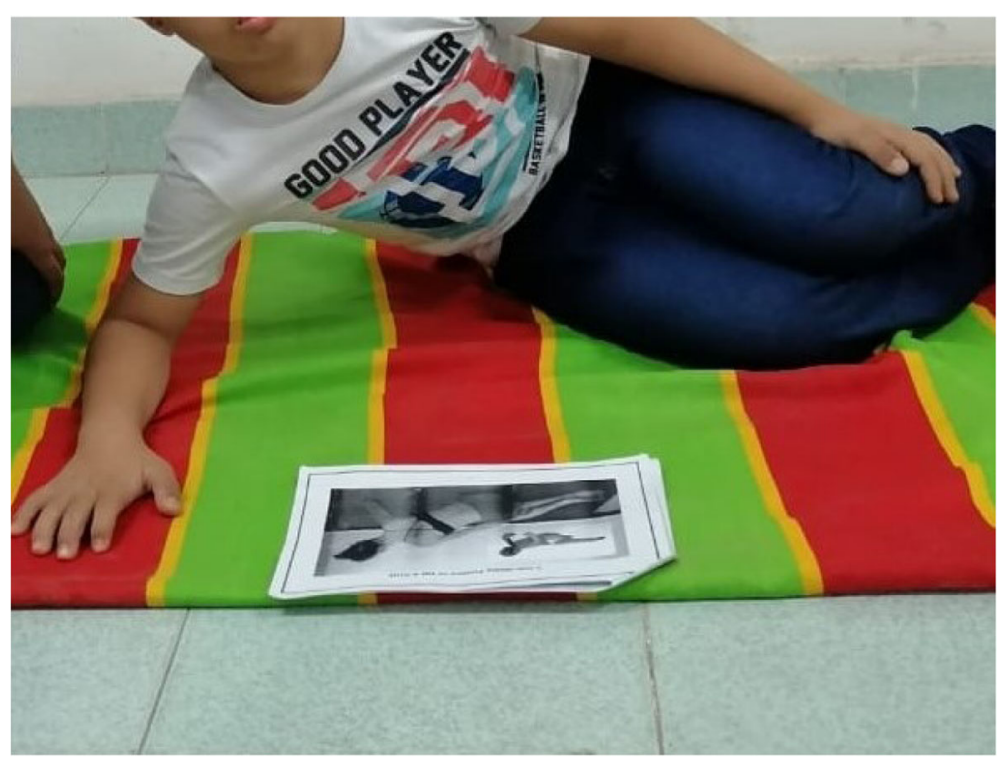

Fig. 5 Side sitting on non-dominant hand

was statistically significant for dominant and nondominant hands (0.001 and 0.003 , respectively), also time $\times$ group interaction effect was also significant (0.0001) as shown in Table 2.

\section{Discussion}

Hand function is considered the most important function of the upper limb that requires proper muscular activities of the whole limb. Literature review stated the fact that, during functional tasks, proximal to distal activation of muscles occurs [34]. So this study investigated the effect of strengthening of shoulder stabilizer muscles on power of hand grip in children with DS. The results of this study revealed that both vocational school activities and strengthening exercise for shoulder stabilizer muscles had significant effect on power of hand grip and different pinch grasps also, adding strengthening exercises to vocational school activities produce more significant effect. These results come in agree with other studies which postulated that coordinated control of shoulder girdle muscles is important for proper positioning of hand that required for delicate functions [23, 35]. Studies stated that energy development and flow follow sequencing from proximal to distal and called kinetic

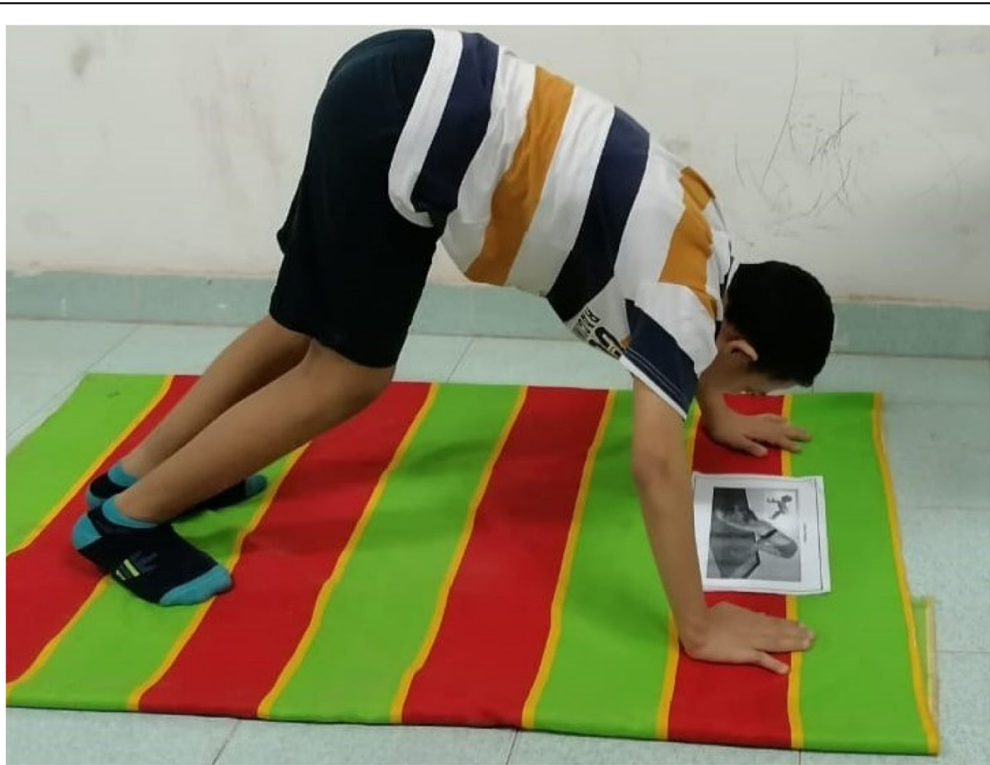

Fig. 6 Bear exercise 
Table 1 Demographic data of the children

\begin{tabular}{|c|c|c|c|}
\hline Demographic data & Study group & Control group & $P$ value \\
\hline Age (years) & $12.13 \pm 2.03$ & $12.2 \pm 2.14$ & 0.93 \\
\hline Weight (kg) & $44.73 \pm 10.87$ & $45.6 \pm 6.63$ & 0.79 \\
\hline Height (m) & $135.6 \pm 12.91$ & $136.86 \pm 8.41$ & 0.75 \\
\hline IQ & $55.66 \pm 4.82$ & $55.46 \pm 3.97$ & 0.9 \\
\hline \multirow[t]{2}{*}{ Gender } & 7 (46.67\%) & $8(53.33 \%)$ & 0.71 \\
\hline & $8(53.33 \%)$ & $7(46.67 \%)$ & \\
\hline
\end{tabular}

chain; any disturbance or change in the kinetic chain leads to affection of the function of the distal segment $[34,36]$. So this confirms that stable proximal shoulder girdle leads to optimal recruitment of hand muscles and explains the positive correlation that found between the hand grip strength and the isokinetic peak torque of shoulder stabilizing muscles in adults and in stroke patients [37, 21]. Hodder and Keir [38] stated that during gripping a motor control command evoked and draw out activity in the proximal shoulder muscles. These make it feasible to train and strength shoulder muscles to improve power of hand grip. Godoy and Barros [16] verified that there is a significant decrease of grip strength in DS adults when compared with others; also, Paula et al. [14] stated that there is $40 \%$ reduction of hand grip strength in child aged 7-9 years with DS when compared with other healthy children. This may be due to different factor as hypotonia, laxity of ligaments, the short hands with short fingers, and single deep crease across the palm of the hand [8]. The proximal dynamic neuromuscular stabilization exercises used in this study provides equal loading on thenar and hypothenar muscles of the hands with fingers extended which improves power of hand grip and pinch strength; also, it offers optimal trunk muscle stabilization which fixate the shoulder girdle muscles and in turn allow proper coactivation of the whole upper limb muscle including shoulder stabilizer and elbow stabilizer muscles that influences the power of hand grip and this gives explanation of improving hand grip strength and pinch grip strength in the study group.

\section{Limitations}

This study was limited to only one school for children with special needs due to variation of vocational school

Table 2 Results of a $2 \times 2$ mixed-model ANOVA

\begin{tabular}{|c|c|c|c|}
\hline \multicolumn{2}{|l|}{ Source of variance } & \multirow{2}{*}{$\begin{array}{l}\boldsymbol{F} \text { value } \\
6.25\end{array}$} & \multirow{2}{*}{$\frac{P \text { value }}{<0.01^{*}}$} \\
\hline Grip strength $(\mathrm{kg})$ : dominant hand & Between subjects (group) & & \\
\hline & Within subjects (time) & 194.38 & $<0.0001^{*}$ \\
\hline & Time $\times$ group & 59.23 & $<0.0001^{*}$ \\
\hline \multirow[t]{3}{*}{ Grip strength $(\mathbf{k g})$ : non-dominant hand } & Between subjects (group) & 5.64 & $<0.02^{*}$ \\
\hline & Within subjects (time) & 448.03 & ${ }^{<} 0.0001^{*}$ \\
\hline & Time $\times$ group & 167.4 & $<0.0001^{*}$ \\
\hline \multirow[t]{3}{*}{ Lateral pinch (kg): dominant hand } & Between subjects (group) & 5.27 & $<0.02^{*}$ \\
\hline & Within subjects (time) & 486.34 & $<0.0001^{*}$ \\
\hline & Time $\times$ group & 122.73 & $<0.0001^{*}$ \\
\hline \multirow[t]{3}{*}{ Lateral pinch (kg): don-dominant hand } & Between subjects (group) & 7.74 & $<0.01^{*}$ \\
\hline & Within subjects (time) & 469.2 & $<0.0001^{*}$ \\
\hline & Time $\times$ group & 166.85 & $<0.0001^{*}$ \\
\hline \multirow[t]{3}{*}{ 2-point pinch (kg): dominant hand } & Between subjects (group) & 12.78 & $<0.001^{*}$ \\
\hline & Within subjects (time) & 360.28 & $<0.0001^{*}$ \\
\hline & Time $\times$ group & 55.74 & $<0.0001^{*}$ \\
\hline \multirow[t]{3}{*}{ 2-point pinch $(\mathrm{kg})$ : non-dominant hand } & Between subjects (group) & 12.83 & $<0.001^{*}$ \\
\hline & Within subjects (time) & 508.52 & $<0.0001^{*}$ \\
\hline & Time $\times$ group & 90.65 & $<0.0001^{*}$ \\
\hline \multirow[t]{3}{*}{ 3-point pinch $(\mathrm{kg})$ : dominant hand } & Between subjects (group) & 14.51 & $<0.001^{*}$ \\
\hline & Within subjects (time) & 254.91 & $<0.0001^{*}$ \\
\hline & Time $\times$ group & 106.91 & $<0.0001^{*}$ \\
\hline \multirow[t]{3}{*}{ 3-point pinch (kg): non-dominant hand } & Between subjects (group) & 10.26 & $<0.003^{*}$ \\
\hline & Within subjects (time) & 380.57 & $<0.0001^{*}$ \\
\hline & Time $\times$ group & 113.94 & $<0.0001^{*}$ \\
\hline
\end{tabular}

*Significant at $a=0.05$ 
activities given in the rest of other schools. Another limitation was the exclusion of children with severe IQ level as they could not be able to understand the evaluation procedure and follow the exercise program.

\section{Conclusion}

Shoulder stabilization exercises and regular vocational school activities have a positive effect on different grip strength in children with Down syndrome.

\section{Abbreviation}

DS: Down syndrome; DNS: Dynamic neuromuscular stabilization

\section{Acknowledgements}

Not applicable

\section{Authors' contributions}

EW performed the exercise program for children and applied the pre- and post-treatment assessment. NS share in the application of exercise program and the assessment procedure, made the data analysis and interpretation and was a major contributor in writing the manuscript. Both authors were shared in formulation of the idea of the study. All authors have read and approved the manuscript

\section{Funding}

Not applicable

\section{Availability of data and materials}

The datasets used and/or analyzed during the current study are available from the corresponding author on reasonable request.

\section{Ethics approval and consent to participate}

This study was approved by ethical committee of the Faculty of Physical Therapy, Beni-Suef University, Egypt (No. BSUPT07), and registered in clinical trial registration website and registration number was PACT R201907896910981.

\section{Consent for publication}

All parents of the participating children in this study were informed about the nature and purpose of this study and signed a written consent form including their acceptance for participation of their children and publication of the study before starting the study procedure.

\section{Competing interests}

The authors declare that they have no competing interests.

\section{Author details}

${ }^{1}$ Basic Science Department, Faculty of Physical Therapy, Egyptian Chinese University, Cairo 11765, Egypt. ${ }^{2}$ Fellow of Physical Therapy at Elsahel teaching hospital, Cairo, Egypt. ${ }^{3}$ Department of physical therapy for Women and Child health, Faculty of Physical Therapy, Beni-Suef University, Beni-Suef, Egypt.

Received: 23 May 2020 Accepted: 1 October 2020

Published online: 03 December 2020

\section{References}

1. Gupta S, Rao BK, Kumaran SD. Effect of strength and balance training in children with Down's syndrome: a randomized controlled trial. Clin Rehabil. 2011;25(5):425-32.

2. Ottenbacher KJ, Short MA. Vestibular processing dysfunction in children. New York, NY: The Haworth Press; 1985.

3. Sherman SL, Allen EG, Bean LH, Freeman SB. Epidemiology of Down syndrome. Ment Retard Dev Disabil Res Rev. 2007;13(3):221-7.

4. Skallerup SJ. Babies with Down syndrome: a new parent's guide. Bethesda: Woodbine House; 2008.

5. Lewis $C L$, Fragala-Pinkham MA. Effects of aerobic conditioning and strength training on a child with Down syndrome: a case study. Pediatr Phys Ther. 2005;17(1):30-6.
6. Pangalos C, Avramopoulos D, Blouin JL, Raoul O, de Blois MC, Prieur M, et al. Understanding the mechanism(s) of mosaic trisomy 21 by using DNA polymorphism analysis. Am J Hum Genet. 1994;54(3):473-81.

7. Antonarakis SE, Epstein CJ. The challenge of Down syndrome. Trends Mol Med. 2006;12(10):473-9.

8. Bull MJ. Committee on Genetics. Health supervision for children with Down syndrome. Pediatrics. 2011;128(2):393-406.

9. Mercer VS, Lewis CL. Hip abductor and knee extensor muscle strength of children with and without Down syndrome syndrome. PediatrPhysTher. 2001;13(1):18-26.

10. Pitetti $\mathrm{KH}$, Climstein M, Mays MJ, et al. Isokinetic arm and leg strength of adults with Down syndrome: a comparative study. Arch Phys Med Rehabil. 1992;73:847-50

11. Croce RV, Pitetti $\mathrm{KH}$, Horvat $\mathrm{M}$, et al. Peak torque, average power, and hamstrings/quadriceps ratios in nondisabled adults and adults with mental retardation. Arch Phys Med Rehabil. 1996;77:369-72.

12. Puszczałowska-Lizis E, Nowak K, Omorczyk J, Ambroży T, Bujas P, Nosiadek L. Foot structure in boys with Down syndrome. Biomed Res Int. 2017:1-6.

13. Chumlea WC, Malina RM, Rarick GL, Seefeldt VD. Communalities for rates of diaphyseal elongation of short bones of the hand of children with Down syndrome. Am J Phys Anthropol. 1980;53(1):129-31.

14. Paula AP, Silvana MB, Raquel C, Denise LV, Fátima AC. Grip strength and manual dexterity in Down syndrome children. FisioterPesqui. 2013;20(3): 278-85.

15. Rebecca J, Ankita D, Rajani PM. Grip and pinch strength in children with Down syndrome. Hand Therapy. 2016;21(3):85-9.

16. Godoy JR, Barros JF. Força de preensão palmar emportadores da síndrome de Down e análise dos músculosenvolvidosnestemovimento [Palmer force in Down syndrome people. Analysis of involved muscles]. Acta Cir Bras. 2005; 20 (Supl. 1), 159 - 166.

17. Su CY, Lin JH, Chien TH, Cheng KF, Sung YT. Grip strength in different positions of elbow and shoulder. Arch Phys Med Rehabil. 1994;75(7):812-5.

18. Jemyung S, Minchull P, Sangyeol L, Myounghee L, Hwanhee Kim. The effects of shoulder stabilization exercise and shoulder isometric resistance exercise on shoulder stability and hand function. J Phys Ther Sci. 2010;22 (3), $227-232$.

19. Mandalidis D, O'Brien M. Relationship between hand-grip isometric strength and isokinetic moment data of the shoulder stabilisers. J Bodyw Mov Ther. 2010;14(1):19-26.

20. Tae-Won Y, Byoung-Hee L. Effects of hand grip strength on shoulder muscle activity in breast cancer patients. Phys TherRehabil Sci. 2016;5(2):95100.

21. Nascimento LR, Polese JC, Faria CD, Teixeira-Salmela LF. Isometric hand grip strength correlated with isokinetic data of the shoulder stabilizers in individuals with chronic stroke. J Bodyw Mov Ther. 2012;16(3):275-80.

22. Jančíková $\mathrm{V}$, Opavský J, Dráč $\mathrm{P}$, Krobot A, Čižmář I. The effect of activation of the shoulder girdle muscles on functional outcomes of rehabilitation in patients with surgically treated distal radius fractures. Acta ChirOrthopTraumatol Cech. 2017. 84(2):114-9.

23. Alena K, Jan D, Pavel K, Angie S, Ross A. Effects of shoulder girdle dynamic stabilization exercise on hand muscle strength. Isokinetics Exercise Science. 2015;23(2015):21-32

24. Faroog M, Khan AA. Effect of shoulder rotation, upper arm rotation and elbow flexion in a repetitive gripping task. Work. 2012;43:263-78. https://doi. org/10.3233/WOR-2012-1391.

25. Hillman TE, Nunes QM, Hornby ST, Stanga Z, Neal KR, Rowlands BJ, et al. A practical posture for hand grip dynamometry in the clinical setting. Clin Nutr. 2005;24:224-8. https://doi.org/10.1016/j.clnu.2004.09.013.

26. Oxford KL. Elbow positioning for maximum grip performance. J Hand Ther. 2000;13:33-6. https://doi.org/10.1016/S0894-1130(00)80050-2.

27. Richards LG, Olson B, Palmiter-Thomas $P$. How forearm position affects grip strength. Am J OccupTher. 1996 Feb;50(2):133-8. https://doi.org/10.1016/ S0003-9993(97)90143-X

28. Kattel BP, Fredericks TK, Fernandez JE, Lee DC. The effect of upper-extremity posture on maximum grip strength. Int J Ind Ergon. 1996;18:423-9. https:// doi.org/10.1016/0169-8141(95)00105-0.

29. Nascimento LR, Polese JC, Faria CD, Teixeira-Salmela LF. Isometric hand grip strength correlated with isokinetic data of the shoulder stabilizers in individuals with chronic stroke. J Bodyw Mov Ther. 2012 Jul;16(3):275-80. https://doi.org/10.1016/j.jbmt.2012.01.002 
30. Peolsson A, Hedlund R, Oberg B. Intra- and inter tester reliability and reference values for hand strength. J Rehabil Med. 2001;33(1):36-41.

31. American Medical Association. Guides to the evaluation of permanent impairment 1993;64-65.

32. Mathiowetz V, Kashman N, Volland G, Weber K, Dowe M, Rogers S. Grip and pinch strength: normative data for adults. Arch Phys Med Rehabil. 1985; 66(2):69-74.

33. Frank C, Kobesova A, Kolar P. Dynamic neuromuscular stabilization \& sports rehabilitation. Int J Sports Phys Ther. 2013;8(1):62-73.

34. Devika B, Husain JK, Ujwal Y, Siddhi T. Effects of dynamic scapular muscle exercises on grip strength in young adults. IJARD. 2018;3(1):289-95.

35. Alexander CM, Miley R, Harrison PJ. Functional modulation of shoulder girdle stability. Exp Brain Res. 2005;161(4):417-22.

36. Aaron Sciascia, Robin Cromwell, Kinetic chain rehabilitation. A theoretical framework, Lexington Clinic, Shoulder Center of Kentucky, 1221 South Broadway, Lexington, KY 40504, USA, 2012.

37. Huijing PA, Baan GC. Myofascial force transmission: muscle relative position and length determine agonist and synergist muscle force. J Appl Physiol. 1985:94(3):1092-107.

38. Hodder JN, Keir PJ. Targeted gripping reduces shoulder muscle activity and variability. J Electromyogr Kinesiol. 2012;22(2):186-90.

\section{Publisher's Note}

Springer Nature remains neutral with regard to jurisdictional claims in published maps and institutional affiliations.

\section{Submit your manuscript to a SpringerOpen ${ }^{\circ}$ journal and benefit from:}

- Convenient online submission

- Rigorous peer review

- Open access: articles freely available online

- High visibility within the field

- Retaining the copyright to your article

Submit your next manuscript at $\boldsymbol{\nabla}$ springeropen.com 